\title{
A INTERDISCIPLINARIDADE COMO ESSÊNCIA NA PROMOÇÃO DA SAÚDE DAS PARTICIPANTES DO PROJETO IDADE ATIVA
}

\author{
LA INTERDISCIPLINARIEDAD COMO ESENCIA EN LA PROMOCIÓN DE LA \\ SALUD DE LOS PARTICIPANTES DEL PROYECTO DE LA EDAD ACTIVA
}

\author{
INTERDISCIPLINARITY AS ESSENCE IN PROMOTING THE HEALTH OF \\ PARTICIPANTS OF THE ACTIVE AGE PROJECT
}

\author{
Viviany Caetano Freire AGUIAR ${ }^{1}$ \\ Luiz Carlos DA SILVA JUNIOR ${ }^{2}$ \\ Stela Lopes SOARES ${ }^{3}$
}

RESUMO: A interdisciplinaridade na área da saúde coletiva vem sendo colocada como um importante requisito no sistema de saúde. Este trabalho objetiva relatar experiência no Curso de Educação Física no Projeto de Extensão Idade Ativa, em que procura salientar a magnitude de um trabalho interdisciplinar na promoção da saúde a um público de terceira idade. As atividades do projeto acontecem duas vezes por semana na Academia de Ginástica de Sobral (AGIS) sobre a colaboração de acadêmicos do Curso de Educação Física e Enfermagem e o então coordenador do projeto pela Universidade Estadual Vale do Acaraú (UVA). Para analisar a experiência colocada em prática, foi utilizada a observação participante, anotações em diário de campo, memorial fotográfico e análises dos relatórios mensais. A partir das informações coletadas, foram ponderados quatro eixos de discussão. Conclui-se então que o trabalho interdisciplinar possui fragilidades. E para seu melhor resultado, são necessários aprimoramentos no sistema de formação dos profissionais. Os projetos curriculares acabam tornando-se base dessa estratégia, possibilitando assim, uma melhor qualificação dos futuros profissionais e consequentemente resultados ao público trabalhado.

PALAVRAS-CHAVE: Interdisciplinaridade. Promoção da saúde. Terceira idade.

RESUMEN: La interdisciplinariedad en el área de la salud colectiva se ha puesto como un requisito importante en el sistema de salud. Este trabajo pretende reportar experiencia en el curso de la educación física en el proyecto de extensión edad activa, en el que se busca destacar la magnitud de un trabajo interdisciplinario en la promoción de la salud a un público de las personas mayores. Las actividades del proyecto suceden dos veces por semana en la Academia de gimnasia de Sobral (AGIS) sobre la colaboración de académicos del curso de educación física y enfermería y el

\footnotetext{
${ }^{1}$ Centro Universitário INTA (UNINTA), Sobral, CE - Brasil. Orientadora Educacional no curso de Educação Física. ORCID: <http://orcid.org/0000-0001-6982-3847>. E-mail: viviany_cfa@ hotmail.com.

${ }^{2}$ Universidade Estadual Vale do Acaraú (UVA), Sobral, CE - Brasil. Prof. Dr. no Curso de Educação Física da Universidade Estadual Vale do Acaraú (UVA). ORCID: <http://orcid.org/0000-0002-56851600>. E-mail: lcjpersonal@ hotmail.com.

${ }^{3}$ Centro Universitário INTA (UNINTA), Sobral, CE - Brasil. Profa. Me. no Curso de Educação Física. ORCID: <http://orcid.org/0000-0002-5792-4429>. E-mail: stelalopesoares@ hotmail.com.
} 
entonces Coordinador del proyecto por la Universidad Estatal Vale do Acaraú (uva). Para analizar la experiencia puesta en práctica, se usó la observación de los participantes, notas del diario de campo, memoria fotográfica y análisis de reportes mensuales. A partir de la información recolectada, se pesaron cuatro ejes de discusión. Por lo tanto, se concluye que el trabajo interdisciplinario tiene debilidades. Y para su mejor resultado, se necesitan mejoras en el sistema de formación de los profesionales. Los proyectos curriculares terminan convirtiéndose en la base de esta estrategia, permitiendo así una mejor calificación de futuros profesionales y consecuentemente resultados al público trabajado.

PALABRAS CLAVE: Interdisciplinariedad. Promoción de la salud. Tercera edad.

ABSTRACT: The interdisciplinarity in the area of collective health has been placed as an important requirement in the health system. This work aims to report experience in the course of physical education in the extension project active age, where seeks to emphasize the magnitude of an interdisciplinary work in the promotion of health to a public of the elderly. The activities of the project happen twice a week at the Academy of Gymnastics of Sobral (AGIS) on the collaboration of academics of the course of physical education and nursing and the then coordinator of the project by the Universidade Estadual Vale do Acaraú (UVA). To analyze the experience put into practice, participant observation, Field Journal notes, photographic Memorial and monthly reports analysis was used. From the information collected, four axes of discussion were weighed. It is therefore concluded that interdisciplinary work has weaknesses. And for its best result, improvements are needed in the training system of professionals. The curricular projects end up becoming the basis of this strategy, thus enabling a better qualification of future professionals and consequently results to the public worked.

KEYWORDS: Interdisciplinarity. Health promotion. Third age.

\section{Introdução}

A Organização Mundial de Saúde (OMS) define saúde não apenas como a ausência de doenças, mas como uma situação de perfeito bem-estar físico, mental e social. Esse conceito se trata de uma definição considerada irreal por que, ao indicar "perfeito bem-estar", acaba sendo remetida a uma ilusão. O que é "perfeito bem-estar?" e por acaso é possível caracterizar-se a "perfeição"?

Novas concepções sobre saúde vão surgindo, acreditam que para o alcance dos níveis de saúde, precisam ser levadas construções de práticas assistenciais e sistemas de saúde característicos. Costa (2007), afirma que os elementos a quem cabiam os cuidados de saúde, a divisão das tarefas, a apropriação dos conhecimentos sobre saúde e sua transmissão foram se modificando continuamente.

RPGE- Revista on line de Política e Gestão Educacional, Araraquara, v. 22, n. 2, p. 469-481, maio/ago., 2018. ISSN: 1519-9029. DOI: 10.22633/rpge.v22.n2.maio/ago.2018.10851 
O trabalho interdisciplinar é um modelo de trabalho que surgiu no âmbito da saúde como estratégia de aprimorar a qualidade da assistência à saúde, de forma a promover uma maior integralidade, que pressupõe tanto o reconhecimento das distintas dimensões relacionadas com o processo saúde-doença. Segundo Mendes (2008) a saúde como integridade e integralidade não permite a sua fragmentação como saúde física, mental e social e, portanto, parte-se de uma visão que supõe entendê-la na interface da grande diversidade de disciplinas. A interdisciplinaridade é algo buscado e bem desejado, principalmente no campo da saúde, mas ainda não tão atingido.

Conceituar a interdisciplinaridade não é tão simples, pois se trata de um assunto vasto e complexo, possibilitando várias formas de interpretação e dúvidas. Para Gattas (2005), essa incompreensão vem da falta de experiência vivida e explicitada, e sua prática concreta sendo ainda um processo incipiente na elaboração do saber, na atividade de ensino e de pesquisa e na ação social.

Para que ocorra uma boa compreensão e assim ser colocada em prática sem dificuldade, é necessário que haja uma interação da teoria com a prática. Gattas (2005 apud JAPIASSU, 1976) recomenda que, para se precisar o sentido do termo "interdisciplinar", é preciso saber o que venha a ser uma disciplina. Sendo assim, falar de interdisciplinaridade é falar da interação de disciplina.

Oliveira (2011) sustenta a ideia de que quando falamos em interdisciplinaridade, estamos de algum modo, nos referindo a uma espécie de interação entre as disciplinas ou áreas do saber. Ainda assim, essa interação pode acontecer em níveis de complexidade diferentes.

E para ocorrer a diferenciação desses níveis que os termos como multidisciplinaridade, interdisciplinaridade, entre outros, foram criados. Vale salientar que suas distinções de conceitos se fazem necessárias.

$\mathrm{Na}$ multidisciplinaridade, recorremos a informações de várias matérias para estudar um determinado elemento, sem a preocupação de interligar as disciplinas entre si. Na interdisciplinaridade, estabelecemos uma interação entre duas ou mais disciplinas (OLIVEIRA, 2011).

Oliveira (2011), afirma que se torna evidente a necessidade da aplicação da interdisciplinaridade nos campos de atuação, seja durante a formação acadêmica, seja durante as ações e protagonismos da prática.

O trabalho interdisciplinar na saúde ocorrerá de maneira eficiente se houver o preparo dos profissionais ainda enquanto acadêmicos para suprir as necessidades que 
serão impostas. Gattas (2005), afirma que a universidade, como formadora de recursos humanos para suprir as necessidades da sociedade, tem papel relevante na formação de profissionais do setor saúde como, também, de outras áreas.

Esse preparo ainda na graduação poderá implicar em um profissional mais ativo, dinâmico, que saiba buscar o conhecimento, com visão integral do ser humano, ampliação do conceito de saúde, doença e cuidado.

Neste mesmo sentido, o Projeto de Extensão Idade Ativa da Universidade Estadual Vale do Acaraú (UVA), entende a necessidade de integração da universidade com seus componentes curriculares envolvidos no processo de formação dos futuros profissionais de Educação Física e Enfermagem.

Visto a importância do diálogo entre teoria e prática e as necessidades e importância de conhecimentos técnico-científicos vislumbrando uma qualificação profissional que compreenda satisfatoriamente sua intervenção enquanto agente de transformação social e construção de um novo modelo de sociedade, capaz de superar os mais difíceis obstáculos que surgirem.

Este projeto beneficia idosas que residem em bairros do município de Sobral, Ceará. No qual buscam promoção de saúde e melhor qualidade de vida vinculada à prática de exercício físico a partir da integração de acadêmicos do curso de Educação física e Enfermagem.

A população idosa se encontra em uma época de longevidade. Segundo estimativa do Instituto Brasileiro de Geografia e Estatística (IBGE 2010), o país já tem 20,6 milhões de idosos. Número que representa $10,8 \%$ da população total do país. A expectativa é que, em 2060, o Brasil tenha 58,4 milhões de pessoas idosas (26,7\% do total). A expectativa de vida dos brasileiros pulará de 75 anos em 2013 para 81 anos em 2060, com as mulheres vivendo em média, 84,4 anos, e os homens 78,03 anos.

Para Mendes (2005) envelhecer é um processo natural que caracteriza uma etapa da vida do homem e dá-se por mudanças físicas, psicológicas e sociais que acometem de forma particular cada indivíduo com sobrevida prolongada. $\mathrm{O}$ aumento progressivo dos anos de vida trás ao indivíduo uma série de mudanças.

Seu corpo já não possui todo um porte físico bem estruturado, pois com o avançar da idade, o corpo sofre alterações de funções que são necessárias para manter o equilíbrio. Seu estado emocional torna-se mais fragilizado, surgem perdas de pessoas queridas abalando assim a questão social. Para isso, é preciso de motivação para seguir 
a vida, muitos encontram na prática de atividades físicas em programas sociais, como é o caso do Projeto Idade Ativa.

Redescobrir suas potencialidades e buscar momentos nos quais os sentimentos possam se expressar, inclusive através do corpo é um dos benefícios que o Projeto Idade Ativa da Universidade Estadual Vale do Acaraú trás às pessoas da terceira idade.

Tendo em vista a importância em ser trabalhado de maneira integrada em que traz como benefício a qualificação de profissionais da área da saúde para que possa promover a saúde da comunidade. O estudo tem como objetivo relatar a importância do processo da integração de acadêmicos do curso de Educação Física e Enfermagem na promoção da saúde das participantes do Projeto de Extensão Idade Ativa.

\section{Metodologia}

Trata-se de um relato de experiência que descrevem vivências acadêmicas e profissionais do Curso de Educação Física, no Projeto de Extensão Idade Ativa, o principal enfoque encontra-se voltado para vislumbrar a importância de um trabalho integrado por acadêmicos ainda em sua formação inicial para a terceira idade, durante o período de dois anos.

O Idade Ativa é um projeto de extensão vinculado à Universidade Estadual Vale do Acaraú, no campus de Ciências da Saúde em Sobral - CE. As atividades eram realizadas na academia Agis (Academia de Ginástica de Sobral), localizada na Av. Comandante Maurocélio Rocha Pontes, $n^{\circ}$. 186, Bairro Derby Club, sendo ela, um dos laboratórios utilizados pelos acadêmicos da universidade.

O projeto funciona com a colaboração voluntaria dos acadêmicos de Educação física e Enfermagem em promover saúde e qualidade de vida, a partir de seus conhecimentos adquiridos na faculdade. Ao todo eram treze monitores, entre acadêmicos de enfermagem e educação física que contribuíram para o projeto com aulas de ginástica comunitária, hidroginástica e educação em saúde as quais são planejadas com consentimento do professor e coordenador do projeto. Utilizou-se como método de coleta de dados para a estruturação deste relato, observação participante, anotações em diário de campo, memorial fotográfico e análises dos relatórios mensais.

Para Queiroz et al (2007), o ato de observar é um dos meios mais frequentemente utilizados pelo ser humano para conhecer e compreender as pessoas, as coisas, os acontecimentos e as situações. O auxílio desse método tornou-se possível 
para uma análise mais incorporada a partir do planejamento e do controle da objetividade dessa técnica científica para o melhor resgate de informações durante o acontecimento do projeto.

As anotações em diário de campo para a realização dos relatórios mensais se evidenciaram como necessárias, em que a partir do contato com as participantes, possibilitou detalhar de forma descritiva as atividades realizadas, principalmente as que eram pertinentes ao objetivo do projeto, tais como, os materiais utilizados, o horário, o local, os comportamentos, emoções e reflexões a cerca das percepções do grupo.

Sendo assim, o período de vivência como monitora no projeto deu-se em março de 2013 a agosto de 2016, durante todas as quartas e sextas feiras exceto períodos de recesso acadêmico e feriados e nos grupos de estudos que acontecem pelas terças feiras.

\section{Histórico do projeto Idade Ativa}

De acordo com Martins (2013) o Projeto de Extensão veio a surgir em 2009, quando o então Professor do Curso de Educação Física Luiz Carlos da Silva sentiu a necessidade de elaborar estratégias que propiciassem a melhoria de conhecimento e de experiência dos alunos do Curso de Pós-graduação em Saúde da Família pela UVA.

Então como uma forma de ajudar nessa questão, foi preparado um Curso de Extensão o qual se intitulou "Intervenção do Profissional de Educação Física na Estratégia Saúde da Família”. No decorrer do Curso houve a presença de algumas turmas de ginástica para idosos.

Martins (2013) declara que a turma em que o Professor Carlos Eduardo Tabosa, até então residente em Saúde da Família, acompanhava nas Pedrinhas continuou a participar das atividades realizadas na sala de ginástica no Centro de Ciências da Saúde.

Portanto, a aceitação da turma pela prática foi um dos grandes motivos para que o Projeto fosse colocado no papel e em seguida fosse posto em prática.

Em 01 de abril de 2011, o grupo de ginástica foi cadastrado no Sistema de Informação e Controle das Ações de Extensão Universitária - SICEX - UVA com o Titulo "Projeto de Extensão Idade Ativa". (MARTINS, 2013)

Hoje o Projeto de Extensão Idade Ativa continua acontecendo às quartas-feiras com a ginástica comunitária, às sextas-feiras com a hidroginástica de sete horas as oito da manhã e educação em saúde na ultima quarta feira de cada mês. 


\section{Caracterização do perfil das participantes}

Atualmente o projeto apresenta 52 participantes cadastradas, todas residentes na cidade de Sobral, compreendendo os bairros Pedrinhas, Sinhá Sabóia, Centro, Parque Silvana II, Cohab I e II, Derby e Campo dos Velhos.

O público envolvido apresenta um perfil variado. Assim diagnosticados, há 12 com diabetes, 19 com hipertensão, todos controlados.

Além disso, existem ainda 09 idosas com osteoporose, uma com miastenia grave, 02 com mal de Parkinson e 06 participantes sem nenhum diagnóstico de problemas de saúde.

Visualiza-se ainda em algumas participantes doenças crônicas como: artrose, tendinite, hérnia de disco, labirintite, depressão, entre outras, também neste grupo. Veras (2012) afirma que o idoso tem como característica básica a multiplicidade de doenças crônicas e estas, após sua instalação, não mais regridem. $\mathrm{O}$ projeto tem $\mathrm{o}$ objetivo, vislumbrá-las a uma prática saudável no controle de seus diagnósticos para que não agrave seus quadros.

\section{Resultados e Discussões}

Ao analisar as informações coletadas, os dados foram agrupados em quatro eixos de discussão, sendo eles: Impressões diante do processo de educação em saúde; $O$ exercício físico trabalhado de maneira integrada; Aprendendo novos saberes em vista à promoção de saúde; Religiosidade e Espiritualidade X Integração.

\section{Impressões diante do processo de educação em saúde}

A educação em saúde surgiu recentemente no projeto como mais uma estratégia de elevar a qualidade de vida e consequentemente da saúde a partir de ações transmitidas para as participantes.

Fernandes (2010) afirma que a saúde e a educação estão intimamente articuladas, pois são vistas como complementares e essenciais para o progresso da estratégia de saúde.

Para a realização dos momentos procuramos abordar temáticas que possuam relação com a prática do exercício físico e suas patologias, buscando a formação de 
opiniões que contribuam em tomada de decisões conscientes e responsáveis para a execução do exercício físico saudável, como também em seu cotidiano.

A educação em saúde, enquanto prática interdisciplinar possibilita a construção de um vínculo entre as pessoas e os profissionais de saúde, para fins de estabelecimento de metas com vista às mudanças de comportamento, promovendo a saúde e o bem-estar. (SPINATO, 2010)

Foram desenvolvidas oficinas educativas, nas quais discutimos temas variados, a saber: alimentação saudável; a importância do cuidado com o diabetes; autoestima e causas, consequências, tratamentos e tipos de ervas medicinais que favorecem o controle da hipertensão. Essas oficinas eram transmitidas através de cartazes, palestras ministradas por acadêmicos, bem como por profissionais do Curso de Biologia e Nutrição e ainda algumas dinâmicas grupais baseadas no Círculo de Cultura de Paulo Freire.

A concepção dialógica de Freire pode ampliar as fronteiras de atuação da Saúde da família, com maior resolutividade das ações e melhor impacto dos indicadores de saúde e de qualidade de vida da população assistida. (FERNANDES, 2010)

A partir das ações pôde ser observado que as mesmas aceitaram muito bem essa proposta, muitas relataram esse momento como importante para sanar dúvidas, adquirir novos conhecimentos, o que possibilitou a melhora nos hábitos diários e conscientização para a prática de exercício físico saudável.

Diante deste feedback nota-se a importância da integração de informações, profissionais e futuros profissionais para que as participantes tenham um hábito de vida mais saudável.

Sendo assim, entende-se que uma atividade que permeia diálogos nos quais exista a interação e troca de experiência entre participantes e acadêmicos, valorizando o autocuidado que é necessário ao desenvolvimento humano e ao bem estar, tornam-se essenciais ações e estratégias de educação em saúde voltadas aos participantes do projeto em busca do objetivo de informá-los e conscientizá-los da necessidade e importância da adoção de um estilo de vida saudável, da mudança de hábitos e comportamentos de saúde.

\section{O exercício físico trabalhado de maneira integrada}


Quando falamos em exercício físico, infelizmente se pensa somente no Profissional de Educação Física (PEF). A Educação Física ainda se encontra bastante estereotipada quanto ao seu trabalho. Para muitos o exercício físico só envolve um profissional que seja habilitado para movimentar o corpo. Sabe-se que não é só isso, para trabalhar com o corpo de maneira saudável não basta só movimentar, é necessário um conhecimento vasto do corpo humano e um trabalho conjunto envolvendo outros profissionais.

O não reconhecimento do PEF por outros profissionais da saúde gera uma frágil relação no trabalho interprofissional. Embora tenham interesse em atuar em equipe, declararam ter dificuldade em se integrar à mesma. (FALCI, 2013)

Ao analisar a integração dos monitores da educação física e enfermagem frente aos exercícios físicos no projeto Idade Ativa, percebo o quanto os encontramos individualizados. Cada categoria trabalha com o olhar focado diante sua profissão. A Educação Física no repasse da prática do exercício e a Enfermagem no cuidado em disponibilizar assistência às participantes, caso necessário.

O trabalho interdisciplinar envolve cumplicidade, responsabilidade e humildade. Não basta auxiliar um ao outro, deve-se buscar compreender como as divergências podem se entrelaçar e como essa união pode ocasionar um rico trabalho. (GORSK, 2013)

Para Loch (2012) faz-se necessário que os envolvidos estejam abertos ao compartilhamento de conhecimentos. Não podem haver espaços para corporativismos. Mesmo que algumas delimitações dos conhecimentos específicos de cada área precisem e devam ser respeitadas.

Ao olhar frente à interdisciplinaridade para a execução dessas atividades, nota-se que ainda existem problemas de integração. Ambas as categorias se encontram ainda individualizadas e para que ocorra essa integração é necessário que sejam elaboradas estratégias de integração mais eficientes.

\section{Aprendendo novos saberes em vista à promoção de saúde}

Além das atividades oferecidas nas quartas e sextas-feiras às participantes, o projeto possui um grupo de estudo no qual se substancializa a leitura de artigos que discutem o envelhecimento, suas causas e consequências, que tratam das patologias e 
atividade física. Estes estudos visam promover o compartilhamento e a aprendizagem coletiva de conhecimentos sobre relevância estratégica.

Erdmann (2008) entende que o desenvolvimento da pesquisa é uma importante estratégia para o fortalecimento da área como ciência e profissão, pois é importante e necessário exercer uma prática profissional sustentada por uma contínua busca de novos conhecimentos.

Os estudos são realizados a partir de leituras de livros, artigos e apresentações sob supervisão do então coordenador do projeto. A realização desse estudo é de extrema importância, tanto para nós acadêmicos favorecendo uma melhor qualificação profissional, quanto para as participantes que, de uma certa forma, recebem uma atenção bem específica quanto às suas patologias vislumbrando a promoção da saúde.

Silva (2007) diz que a promoção da saúde se trata de uma estratégia de produção de saúde, que deve estimular a articulação entre o pensar e o agir com as demais políticas e tecnologias.

A interdisciplinaridade ainda é um processo difícil dentro do grupo de estudos. Os acadêmicos do Curso de Enfermagem não tiveram a oportunidade de participar devido à recém-mudança de monitores, depois dessas mudanças não retomamos aos grupos de estudo. Acredito que com a retomada, os estudos integrados dos monitores juntamente com o coordenador do projeto, serão de grandes valia para todos, melhorando ainda mais o processo de teoria com a prática de forma integrada.

Essa integração aos estudos poderá ser um fator benéfico na integralidade da prática dos exercícios físicos, pois com o diálogo, trocas de conhecimentos/experiências e estudo de ambos sobre as patologias, com certeza poderá resultar em uma maior integração quanto à prática.

\section{Religiosidade e espiritualidade $\mathrm{x}$ integração}

A Fé é algo bastante presente no projeto. Embora possuam pessoas com distintas crenças, não abrem mão do momento de oração no final das atividades. Fornazari (2010) afirma que a religiosidade e/ou espiritualidade proporcionam um forte auxílio tanto no acolhimento como na procura por significação, aparecendo como variáveis importantes para o enfrentamento da problemática.

RPGE- Revista on line de Política e Gestão Educacional, Araraquara, v. 22, n. 2, p. 469-481, maio/ago., 2018. ISSN: 1519-9029. 
O ápice de agradecer/refletir por mais um dia de vida, de paz, de saúde, da oportunidade em estar naquele exato momento com amigos, construindo mais amizades e o trabalho dos professores, para elas devem sempre ser ressaltados.

Pelas falas, muitas vezes emocionadas, notamos o quão é valioso o Projeto Idade Ativa para cada uma. Relatam que o ato de acordarem cedo e virem de longe, não é somente para realizar a prática exercício físico, para elas às quartas e sextas-feiras são dias de ver os amigos que conquistaram, dias de se divertir, conversar, rir, dançar, brincar, esquecer-se dos problemas que tem em casa e receber a atenção e carinho de todos.

Esse é o momento de maior integração de todos, nessa hora não existe professor e aluno. Existem pessoas possuem um grande carinho e afeto entre cada e refletem ao agradecimento de estarem naquele momento juntos com pessoas queridas.

\section{Considerações finais}

Muitos são os desafios para que o trabalho interdisciplinar se concretize de fato no projeto. Entre os desafios para a superação da prática dessa integralidade, está o compromisso de rever o processo de formação, embora o projeto possibilite essa prática interdisciplinar aos acadêmicos, necessita-se de uma base. E para que isso ocorra, a grade curricular de ambos os cursos deve ser repensada de maneira que viabilize em uma maior interação nos cursos, possibilitando assim, uma formação com maior capacidade de integração enquanto profissionais.

Embora o processo de formação se encontre ainda fragilizado frente à interdisciplinaridade, o projeto Idade Ativa possibilita aos acadêmicos que se fazem como monitores, em vivenciar embora com dificuldades de integração e realmente trabalhando o processo teoria-prática.

Vejo que o trabalho realizado no projeto trouxe muitos ganhos. Entre eles, cito a relação do vínculo entre acadêmicos da Educação Física e Enfermagem, onde possibilitou a quebra de pré-conceitos que infelizmente são estabelecidos entre uma categoria e outra. E isto, de certa forma traz um amadurecimento, propiciando profissionais mais compreensivos e íntegros aos outros.

A junção de conhecimentos e práticas nas atividades dirigidas às participantes evidenciou uma melhor tomada de decisões, maior vinculo afetivo, conscientização, 
novas mudanças de hábitos saudáveis na vida diária e na prática do exercício físico, benefícios estes que permitem uma melhor qualidade de vida e promoção de saúde.

Portanto, embora com algumas dificuldades de integração, percebe-se o quão importante é o trabalho interdisciplinar, não só para as participantes do projeto, mas para os profissionais ou futuros profissionais que poderão desenvolver um trabalho ainda melhor.

\section{REFERÊNCIAS}

COSTA, R. P. Interdisciplinaridade e equipes de saúde: concepções. Mental, Barbacena, v. 5, n. 8, jun., 2007.

ERDMANN, A. L.; LANZONI, G. M. M. Características dos Grupos de Pesquisa da Enfermagem Brasileira Certificados pelo Cnpq de 2005 A 2007. Esc. Anna Nery Rev. Enferm., v. 12, n. 2, p. 316-322, jun., 2008.

FALCI, D. M.; BELISÁRIO, S. A. A inserção do profissional de educação física na atenção primária à saúde e os desafios em sua formação. Comunicação Saúde Educação, v. 17, n. 47, p. 885-99, out./dez., 2013.

FERNANDES, M. C. P.; BACKES, V. M. S. Educação em saúde: perspectivas de uma equipe da Estratégia Saúde da Família sob a óptica de Paulo Freire. Rev. Bras.

Enferm., Brasília, v. 63, n. 4, p. 567-573, jul./ago., 2010.

FORNAZARI, S.A.; FERREIRA R. E. R. Religiosidade/Espiritualidade em Pacientes Oncológicos: qualidade de Vida e Saúde. Psic.: Teor. e Pesq., Brasília, v. 26, n. 2, p. 265-272, abr./jun., 2010.

GATTÁS, M. L. B. Interdisciplinaridade em cursos de graduação da área na saúde da Universidade de Uberaba-Uniube. 2005. Tese (Doutorado em Enfermagem) Escola de Enfermagem de Ribeirão Preto, Universidade de São Paulo, Ribeirão Preto, 2005.

GORSKI, G. M.; PEREIRA, D. L. Profissional de Educação Física: interdisciplinaridade no Programa Saúde da Família. Rev. Ciênc. Ext., v. 9, n. 3, p. 72$81,2013$.

INSTITUTO BRASILEIRO DE GEOGRAFIA E ESTATÍSTICA - IBGE: Censo Demográfico 2010. Características gerais da população, religião e pessoas com deficiência. Rio de Janeiro. 2012. Disponível em: <ftp://ftp.ibge.gov.br/Censos/Censo_Demografico_2010/Caracteristicas_Gerais_Religia o_Deficiencia/caracteristicas_religiao_defi ciencia.pdf>. Acesso em: 07 set. 2017.

LOCH, M. R.; FLORINDO, A. A. A Educação Física e as residências multiprofissionais em saúde. Revista Brasileira de Atividade Física \& Saúde, Pelotas, v. 17, n. 1, p. 81-2, 2012.

RPGE- Revista on line de Política e Gestão Educacional, Araraquara, v. 22, n. 2, p. 469-481, maio/ago., 2018. ISSN: 1519-9029. DOI: $10.22633 /$ rpge.v22.n2.maio/ago.2018.10851 
MARTINS, V. M. G. A prática regular da ginástica e da hidroginástica como coadjuvante no processo do envelhecimento saudável: relato de experiência do projeto de extensão idade ativa em Sobral - CE. Universidade Estadual Vale do Acaraú - UVA, 2013.

MENDES, J. M. R.; LEWGOY, A. M. B.; SILVEIRA E. C. Saúde e interdisciplinaridade: mundo vasto mundo. Revista Ciência \& Saúde, Porto Alegre, v. 1, n. 1, p. 24-32, jan./jun., 2008.

MORAES, M. C. O Pensamento Eco- sistêmico: educação, aprendizagem e cidadania no século XXI. Petrópolis/RJ: Editora Vozes, 2004.

OLIVEIRA, E. R. A. et al. Interdisciplinaridade, trabalho em equipe e multiprofissionalismo: concepções dos acadêmicos de enfermagem. Revista Brasileira de Pesquisa em Saúde, v. 13, n. 4, p. 28-34, 2011.

OMS/UNICEG. Cuidados de Saúde Primários: Relatório da Conferência Internacional sobre Cuidados primários da Saúde. URSS: Alma-Ata. 1978.

QUEIROZ, D. T. et al. Observação participante na pesquisa qualitativa: conceitos e aplicações na área da saúde. Rev Enferm., v. 15, n. 2, p. 276-283, 2007.

SILVA, R. M.; ARAÚJO M. A. L. Promoção da saúde no contexto interdisciplinar. Revista Brasileira em Promoção da Saúde, v. 20, n. 3, p. 141-142, 2007.

SPINATO, I. L.; MONTEIRO L. Z.; SANTOS, Z. M. S. A adesão da pessoa hipertensa ao exercício físico - uma proposta educativa em saúde. Texto Contexto Enferm,

Florianópolis, v. 19, n. 2, p. 256-264, 2010.

VERAS, R. P. Prevenção de doenças em idosos: os equívocos dos atuais modelos. Cad. Saúde Pública, Rio de Janeiro, v. 28, n. 10, p. 1834-1840, out., 2012.

\section{Como referenciar este artigo}

AGUIAR, Viviany Caetano Freire.; DA SILVA JUNIOR, Luiz Carlos.; SOARES, Stela Lopes. A interdisciplinaridade como essência na promoção da saúde das participantes do Projeto Idade Ativa. Revista on line de Política e Gestão Educacional, Araraquara, v. 22, n. 2 , p. 469-481, maio/ago., 2018. ISSN: 1519-9029. DOI: 10.22633/rpge.v22.n2.maio/ago.2018.10851

Submetido em: 04/04/2018

Revisões Requeridas: 05/05/2018

Aprovado em: 17/06/2018 